\title{
Partition Coefficients of Vinyl Chloride between PVC/Liquid/Vapor Phases
}

\author{
C. B. Patel, R. E. Grandin, R. Gupta, E. M. Phillips, C. E. Reynolds, and R. K. S. Chan \\ Plastics $R \&$ D, Air Products and Chemicals, Inc., P. O. Box 538, \\ Allentown, Pennsylvania 18105, U.S.A.
}

(Received February 21, 1978)

\begin{abstract}
The distribution of vinyl chloride monomer (VCM) in solid (unplasticized PVC), liqid (water or a 1:1 water-ethanol mixture) and vapor phases is measured under equilibrium conditions. Because VCM has only recently been found to be a carcinogen and because difficulties have been encountered in the sampling and analysis of VCM in solvents and suspended PVC particles, only very limited data are available in the literature about the partition coefficients of VCM between solid/liquid/vapor phases. The equilibrium distribution of VCM in two contacting phases (solid/water or water/vapor), is reported at different temperatures and concentrations. As the solid phase concentration increases to $100,000 \mathrm{ppm}$, the solid/liquid partition coefficient, $H_{\mathrm{SL}}$, attains a value which is almost indepednent of temperature. The liquid/vapor partition coefficient, $H_{\mathrm{LV}}$, is independent of concentration and varies only with temperature. A 1:1 ethanol-water mixture is used to simulate the food content inside a PVC container. When this fluid mixture is used as the liquid phase, the $H_{\mathrm{SL}}$ value was found to be lower as compared to that for pure water. The results reported in this paper should find application in the study of VCM emission control, stripping of VCM from PVC, pollution from waste streams, and migration of VCM from PVC containers to their food contents.
\end{abstract}

KEY WORDS Vinyl Chloride Monomer / Solubility / Poly(Vinyl

Chloride) / Three Phases / Partial Pressure / Partition Coefficients /

Recently, vinyl chloride has been recognized as a cancer causing agent. Government agencies have proposed stringent regulations regarding its maximum concentrations in air, food content in PVC package, etc. ${ }^{1,2,3}$ Manufacturers of PVC have been looking for better methods of stripping their resins to reduce the VCM content. ${ }^{4}$ The emission of VCM from PVC aqueous slurries, wastewater, PVC powder resins and PVC packages are related to the partition coefficients of VCM between solid/liquid phases, $H_{\mathrm{SL}}$, and between liquid/ vapor phases, $H_{\mathbf{L} T}$. The partition coefficients are the ratios of concentrations in the two contacting phases at equilibrium and thus govern the driving force in the emission processes.

Berens $^{5}$ has reported equilibrium distribution data between PVC solid and vapor phases, $H_{\mathrm{Sv}}$, and between water and vapor phases, $H_{\mathrm{LV}}$. Morano and Gilbert ${ }^{6}$ have reported data on partition coefficient of VCM between PVC solid and various solvents. Daniels and Proctor $^{7}$ have re- ported some calculated values of $H_{\mathrm{SL}}$.

In this paper, we report the equilibrium data of VCM between the three phases. Experiments were carried out in a closed system. The concentration of VCM in two phases were measured and the concentration of VCM in the third phase was calculated by a material balance on VCM. The concentration of VCM in the solid and liquid phases is denoted by $C_{\mathrm{S}}$ and $C_{\mathrm{L}}$ respectively and the partial pressure of VCM in the vapor phase is $\boldsymbol{P}_{\mathrm{VCM}}$. The partition coefficients are defined as follows

$$
H_{\mathrm{SL}}=\frac{C_{\mathrm{L}}}{C_{\mathrm{S}}}, \quad H_{\mathrm{LV}}=\frac{P_{\mathrm{VCM}}}{C_{\mathrm{L}}}, \quad H_{\mathrm{SV}}=\frac{P_{\mathrm{VCK}}}{C_{\mathrm{S}}}
$$

$C_{\mathrm{S}}$ and $C_{\mathrm{L}}$ are reported either in $\mathrm{mol} / \mathrm{ml}$ or $\mathrm{ppm}$ by weight. $\quad P_{\mathrm{VCM}}$ is reported in dyn $/ \mathrm{cm}^{2}$ or psi. A density of $1.4 \mathrm{gm} / \mathrm{m} l$ is used for the unplasticized PVC when converting the units of $C_{\mathrm{s}}$ from ppm to $\mathrm{mol} / \mathrm{ml}$. 


\section{EXPERIMENTAL}

\section{Materials Used}

PVC slurries with different amounts of VCM were obtained directly from suspension polymerization. In certain other cases, the slurries were prepared by mixing dry resin with water (or a $1: 1$ ethanol-water mixture) in an experimental bomb vessel. A known amount of VCM was added to the bomb.

\section{Apparatus and Sampling Procedures}

Two different sampling devices were used to determine the partition coefficients. The first device is referred to as the "internal sampler" and separates the liquid phase from the PVC slurry. $H_{\mathrm{LV}}$ is obtained by analyzing the VCM concentrations in the liquid phase and the supernatant vapor phase. The second device is referred to as the "bomb sampler". It consists of a bomb vessel mounted inside the oven of a gas chromatograph. The bomb contains the solid, liquid, and vapor phases. Once again, $H_{\mathrm{LV}}$ is obtained by analyzing the liquid and vapor phases. Our experimental techniques are confirmed by noting that the two devices yield very comparable $H_{\mathrm{LV}}$ data. The solid/liquid partition coefficient, $H_{\mathrm{SL}}$, is obtained by computing the PVC phase concentration from a material balance on VCM in the bomb.

Internal Sampler. Figure 1 is a sketch of the internal sampler. Figure 2 shows the internal sampler immersed in the slurry in a stripping tank and connected to a gas chromatograph.

The internal sampler consists of a stainless steel pipe fitted with two leak free pistons. The pistons can be retracted or released by the application of vacuum or pressure.

Piston 1 is retracted by the application of a vacuum on the lower side of piston 1 . This creates a vacuum inside the sampler and a volume of the slurry flows into the sampler through the four small ports located symmetrically around and at the mid section of the pipe. The liquid sampling line which runs through piston 2 to sampling valve (line 1 in Figure 2) had been evacuated.

When piston 1 is released by the application of nitrogen pressure through line 2 of Figure 2, the four small ports are blocked off and a volume of the slurry is trapped inside the sampler. A further application of pressure forces the liquid phase

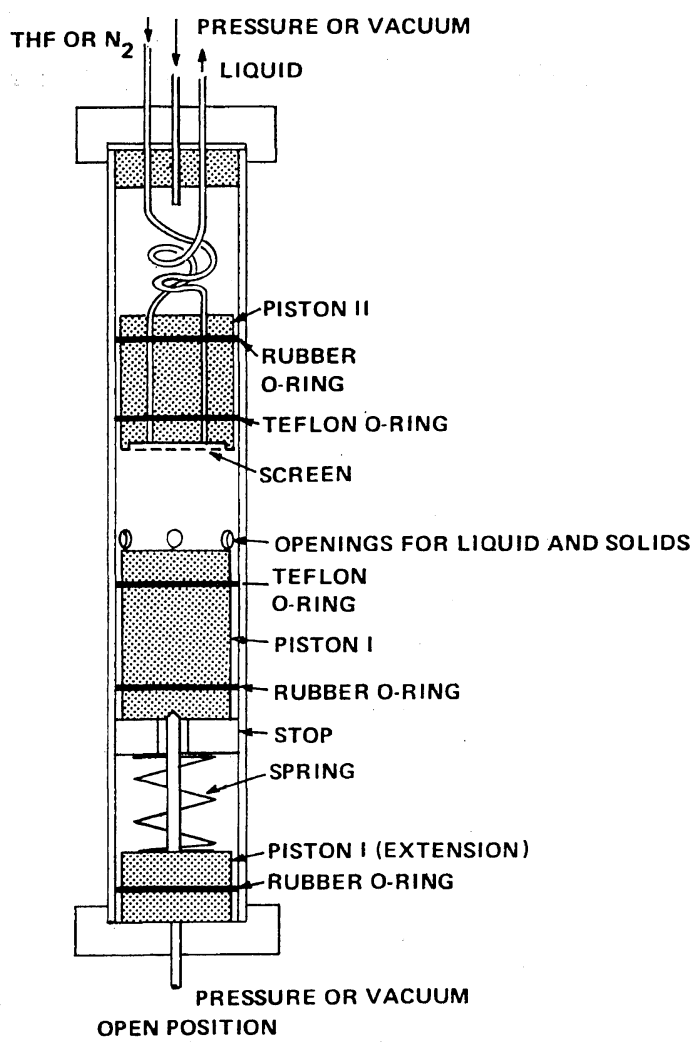

Figure 1. Internal sampler.

through a $10-\mu$ screen that is placed at the lower end of piston 2. The liquid sample is analyzed for VCM concentration in the gas chromatograph as shown in Figure 2.

The vapor sample was analyzed through line 5 (Figure 2). The vapor line must be evacuated before a vapor sample is introduced through valve B. Also, it is necessary to heat the vapor line so that no condensation takes place. This was achieved by circulating a hot solvent within the jacket of the vapor line.

It is also possible to determine the solid/liquid partition coefficient using the internal sampler. To obtain the VCM concentration in the solid phase, the residual wet cake is dissolved in a known amount of tetrahydrofuran (THF). This is achieved by injecting through line 3 (Figure 2) a premeasured quantity of THF with the help of nitrogen pressure. THF dissolves the wet cake very readily. The amount of dissolved PVC in THF can be determined by gel-permeation chro- 


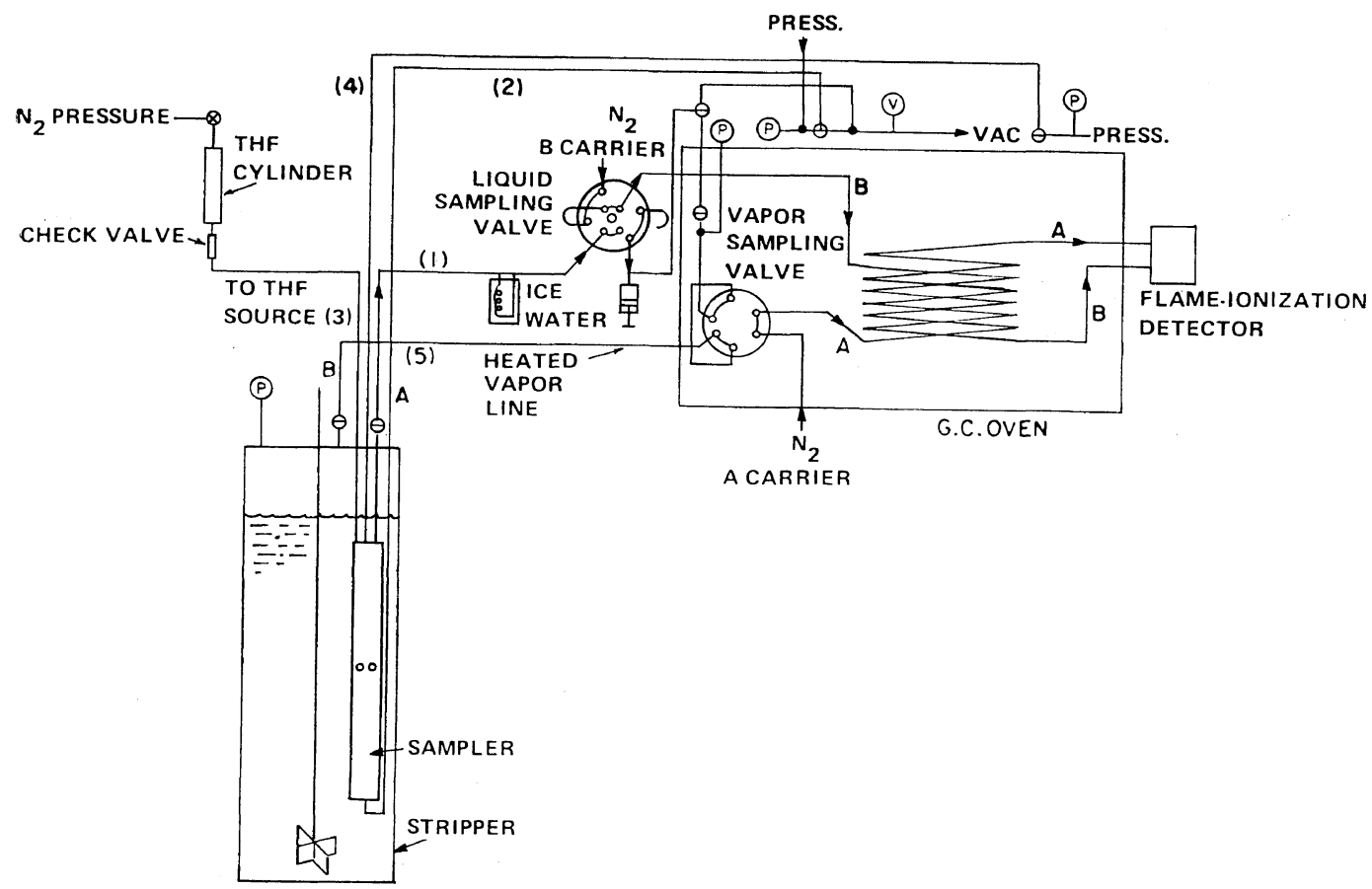

Figure 2. A system for sampling vapor and liquid for vinyl chloride analysis via internal sampler.

matography or by evaporating THF and weighing the residual PVC in an aluminum weighing dish. The concentration of VCM in the THF solution was determined by using the gas chromatography.

It was found that the above procedure for the determination of solid phase concentration is tedious and generally inaccurate. Also, correction must be made for the amount of VCM in the liquid phase in the wet cake. For the above reasons, the solid/liquid partition coefficient is obtained more conveniently by using the bomb sampler that will be described now.

Bomb Sampler. The bomb sampler consists of a stainless steel vessel fitted with a five-way ball valve and placed inside the oven of a gas chromatograph. Figure 3 is a schematic of the bomb vessel and the sampling system. The liquid-sampling loop consists of a liquid-sampling valve and a switching valve. The liquid-sampling valve is placed outside the GC oven. Needle valve 1 helps to isolate the liquid sample from the temperature of the GC oven as shown in Figure 3.

The vapor sampling loop consists of a vapor sampling valve and a switching valve. The vapor- sampling valve is connected to a transducer for the measurement of vapor-phase pressure. The vapor sample is withdrawn into the sampling loop with the bomb vessel in a horizontal position. Opening of the appropriate valves and tilting of the bomb vessel as shown in Figure 3, allow a liquid sample to be withdrawn into the liquidsampling loop. A syringe is connected to the liquid-sampling valve to confirm that a liquidsample has been withdrawn when the bomb vessel is tilted. The liquid and vapor lines can be evacuated or vented by a connection to a vacuum pump.

The bomb sampler is used to determine the partition coefficient of VCM between liquid and vapor phases when no solid phase is present (two-phase experiments). Also it is used to determine the partition coefficients between solid/liquid and liquid/vapor phases when all the three phases are present (three-phase experiments).

For the two-phase experiment, a known amount of water is added to the bomb. The exact weight of water is determined by weighing after air has been evacuated from the bomb by connecting it to the vacuum line for a short time. VCM is added 


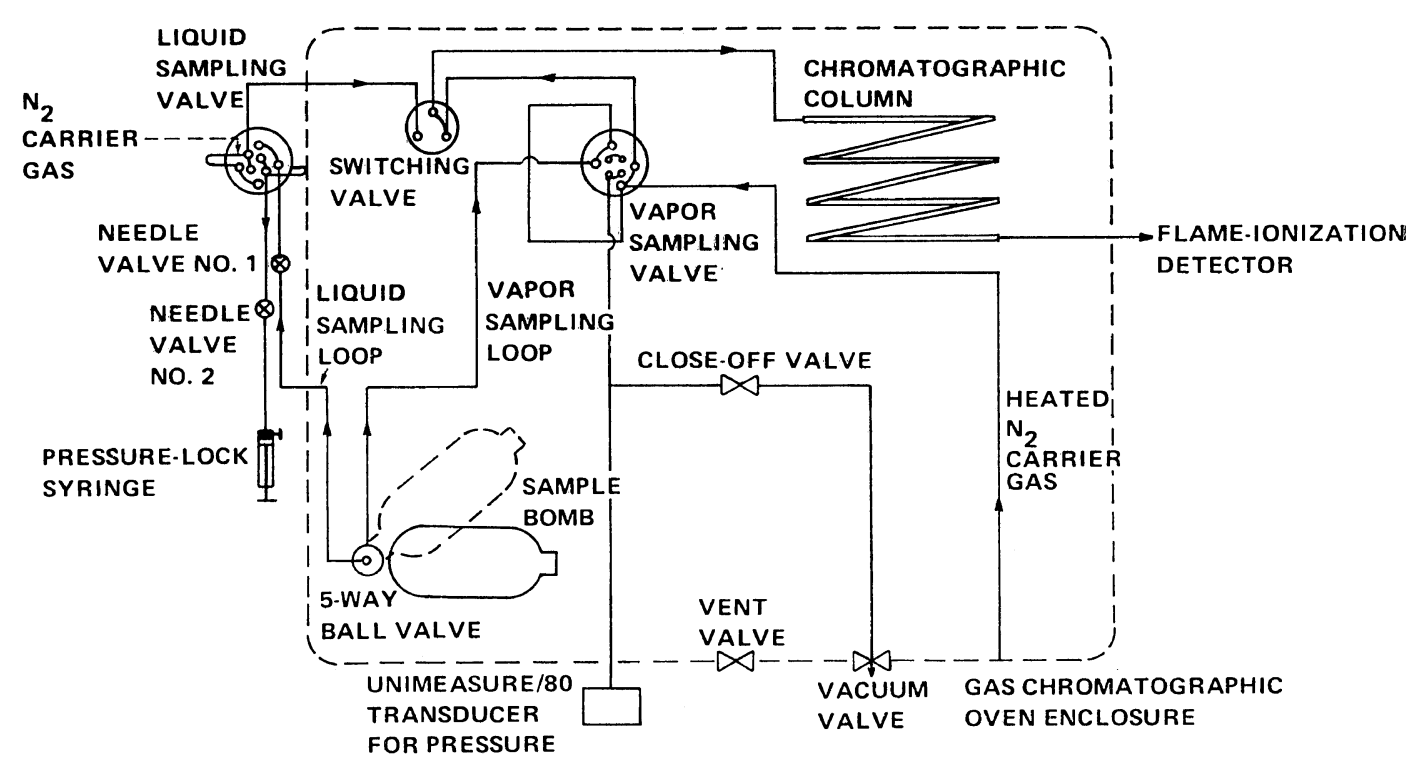

Figure 3. Schematic diagram of sampling system of solid, liquid, and vapor for vinyl chloride analysis.

to the bomb and the amount added is determined by weighing. After equilibrium is established, the liquid and vapor phases are analyzed for VCM concentrations as described above.

It is possible to apply a material balance check on VCM to determine the accuracy of the experimental technique. For this, a known amount of THF was added to the bomb and the contents dissolved in it. The amount of VCM in the bomb was calculated by analyzing the concentration of VCM in THF. The amount of VCM determined by THF analysis was compared with the amount of VCM introduced in the system at the beginning of the experiment. The percent material balance recovery is reported in Table II for the two-phase experiments.

For the three-phase experiments, the concentrations of VCM in the liquid and vapor phases were determined by using the GC. The concentration of VCM in the solid phase was determined by using a material balance on VCM.

In three-phase experiments where the starting material was PVC slurry from suspension polymerization, the amount of VCM in the system was determined by dissolving the contents of the bomb in THF. In these experiments, a material balance check on VCM is not possible because the concentration of VCM in the slurry is unknown. In ex- periment where the slurries were prepared by mixing water with VCM-free dry resin and subsequently adding a known amount of VCM, a material-balance check is possible and is reported.

The major sources of experimental error include a poor analytical accuracy at low concentrations, the possibility of some hysteresis in equilibrium partition at low temperatures as reported by Berens, ${ }^{5}$ and an observed discoloration of the resin and a possible change in the adsorption characteristics when equilibration is carried out for a prolonged time at elevated temperatures.

\section{RESULTS AND CONCLUSIONS}

Both the internal sampler and the bomb sampler were used to determine the liquid/vapor partition coefficients. Figure 4 is a plot of the partial pressure of the VCM vs. the liquid-phase concentration obtained from the two-phase experiments using the bomb sampler. The straight lines in all the figures are based on the least square fitting. The data indicates that $H_{\mathrm{LV}}$ is independent of concentration and is a function of the temperature only. $H_{\mathrm{LV}}$ calculated from Figure 4 is plotted as a function of the inverse of temperature in Figure 5. Also plotted in Figure 5 are the values of $H_{L \mathrm{r}}$ obtained from the internal sampler and the data 


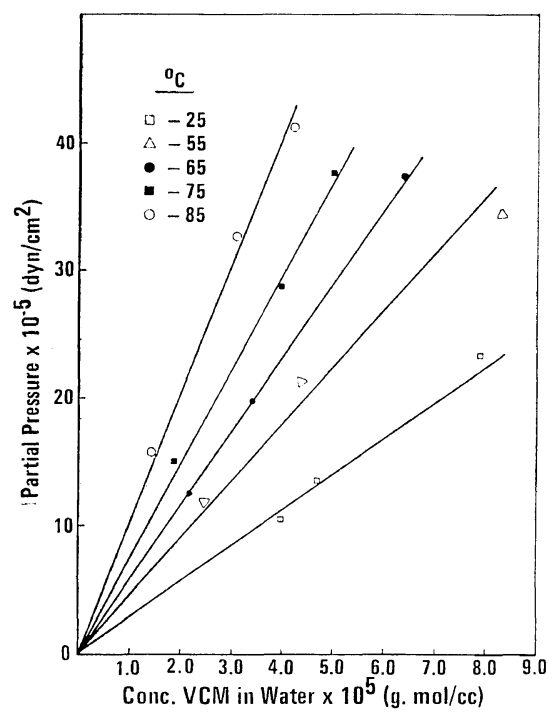

Figure 4. Partial pressure of VCM vs. VCM concentration in water at equilibrium at different temperatures.

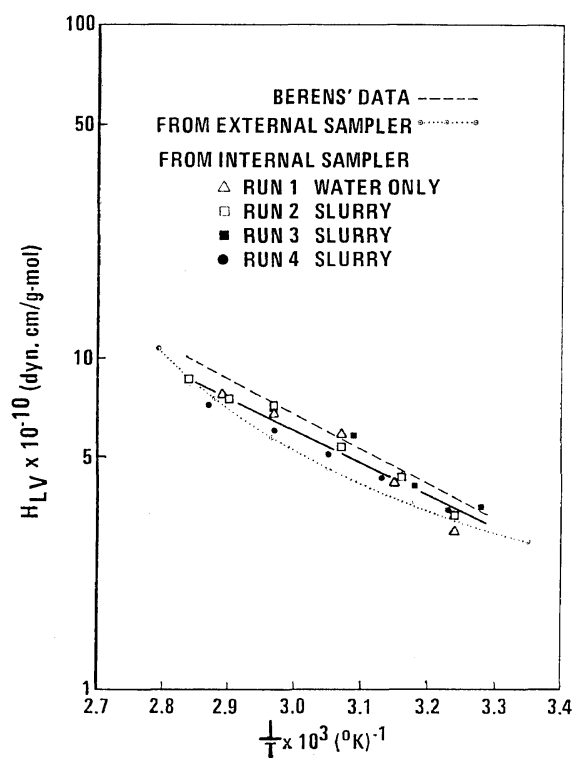

Figure 5. Partition coefficients of VCM in liquid and vapor phases $v s$. inverse temperature.

of Berens. ${ }^{5}$ There is no significant difference in the $H_{\mathrm{LV}}$ data from the two sampling devices. Figure 5 also shows that our values of $H_{\mathrm{LV}}$ are slightly lower than those reported by Berens. ${ }^{5}$ Table I summarizes the $H_{\mathrm{LV}}$ data obtained from the internal sampler. Table II is a summary of

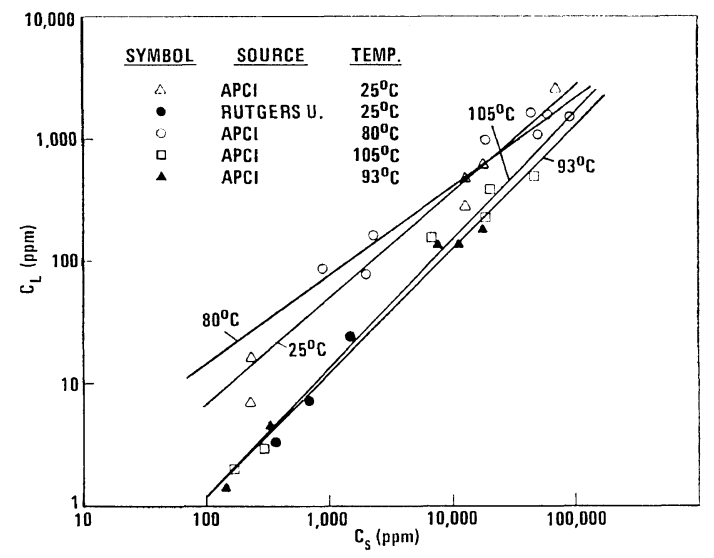

Figure 6. VCM concentrations in unplasticized PVC and water at equilibrium.

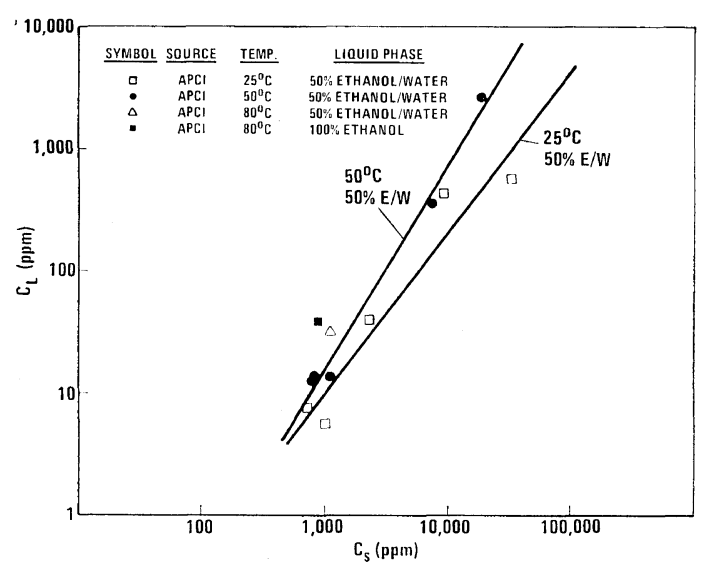

Figure 7. VCM concentrations in unplasticized PVC and $1: 1$ ethanol-water at equilibrium.

the results of the two-phase experiments in the bomb sampler.

Tables III and IV are the results of three-phase experiments using the bomb sampler. In addition to the VCM concentrations and partition coefficients, Tables III and IV also contain the time duration for which a mixture was allowed to equilibrate before samples were withdrawn for VCM analysis. A material-balance check is possible only for the experiments where the slurries were prepared by introducing a known amount of VCM to the bomb (slurries A). As previously explained, no material balance is possible for slurries B. Tables I, II, and III show that the values of $H_{\mathrm{LV}}$ obtained from the three-phase experiments 
are consistent with those obtained from the twophase experiments.

The equilibrium concentrations in solid and liquid phases are plotted in Figure 6 when the liquid phase is water. Figure 7 is a similar plot when the liquid phase is a $1: 1$ ethanol-water mixture.

Figure 6 shows that as the concentration of $\mathrm{VCM}$

Table I. Partition coefficients of VCM between liquid (water)/vapor phases using internal sampler

\begin{tabular}{|c|c|c|c|c|c|}
\hline $\begin{array}{l}\text { Run } \\
\text { No. }\end{array}$ & $\underset{{ }^{\circ} \mathrm{C}}{\mathrm{Temp}}$ & $\begin{array}{c}\text { Partial pressure } \\
\text { of } \mathrm{VCM}\left(P_{\mathrm{VCM}}\right), \\
\text { psi }\end{array}$ & $\begin{array}{c}\text { Concn of } \mathrm{VCM} \\
\text { in water, } \\
\mathrm{mol} / \mathrm{m} l\end{array}$ & $\begin{array}{c}H_{\mathrm{LV}} \\
\mathrm{dyn} \mathrm{cm} / \mathrm{mol}\end{array}$ & $\begin{array}{l}I / T \\
\mathrm{~K}^{-1}\end{array}$ \\
\hline \multirow[t]{5}{*}{1} & 35.0 & 17.79 & $4.102 \times 10^{-5}$ & $2.990 \times 10^{10}$ & $3.24 \times 10^{-2}$ \\
\hline & 44.2 & 20.23 & $3.313 \times 10^{-5}$ & $4.210 \times 10^{10}$ & $3.15 \times 10^{-2}$ \\
\hline & 52.5 & 22.16 & $2.596 \times 10^{-5}$ & $5.885 \times 10^{10}$ & $3.07 \times 10^{-2}$ \\
\hline & 63.0 & 22.56 & $2.330 \times 10^{-5}$ & $6.676 \times 10^{10}$ & $2.97 \times 10^{-2}$ \\
\hline & 73.0 & 24.99 & $2.235 \times 10^{-5}$ & $7.709 \times 10^{10}$ & $2.89 \times 10^{-2}$ \\
\hline \multirow[t]{6}{*}{2} & 35.0 & 16.76 & $3.456 \times 10^{-5}$ & $3.344 \times 10^{10}$ & $3.24 \times 10^{-2}$ \\
\hline & 43.5 & 19.33 & $3.048 \times 10^{-5}$ & $4.373 \times 10^{10}$ & $3.16 \times 10^{-2}$ \\
\hline & 52.5 & 20.74 & $2.670 \times 10^{-5}$ & $5.356 \times 10^{10}$ & $3.07 \times 10^{-2}$ \\
\hline & 63.0 & 23.01 & $2.363 \times 10^{-5}$ & $6.714 \times 10^{10}$ & $2.97 \times 10^{-2}$ \\
\hline & 72.0 & 23.23 & $2.116 \times 10^{-5}$ & $7.569 \times 10^{10}$ & $2.90 \times 10^{-2}$ \\
\hline & 78.5 & 23.95 & $1.917 \times 10^{-5}$ & $8.614 \times 10^{10}$ & $2.34 \times 10^{-2}$ \\
\hline \multirow[t]{3}{*}{3} & 32.0 & 33.97 & $6.630 \times 10^{-5}$ & $3.533 \times 10^{10}$ & $3.28 \times 10^{-2}$ \\
\hline & 41.5 & 36.88 & $6.155 \times 10^{-5}$ & $4.131 \times 10^{10}$ & $3.18 \times 10^{-2}$ \\
\hline & 50.5 & 47.53 & $5.691 \times 10^{-5}$ & $5.758 \times 10^{10}$ & $3.09 \times 10^{-2}$ \\
\hline \multirow[t]{5}{*}{4} & 36.0 & 41.48 & $8.193 \times 10^{-5}$ & $3.491 \times 10^{10}$ & $3.23 \times 10^{-2}$ \\
\hline & 46.0 & 59.09 & $7.921 \times 10^{-5}$ & $4.360 \times 10^{10}$ & $3.13 \times 10^{-2}$ \\
\hline & 54.5 & 54.78 & $7.393 \times 10^{-5}$ & $5.109 \times 10^{10}$ & $3.05 \times 10^{-2}$ \\
\hline & 64.0 & 57.58 & $6.555 \times 10^{-5}$ & $6.056 \times 10^{10}$ & $2.97 \times 10^{-2}$ \\
\hline & 75.0 & 60.43 & $5.762 \times 10^{-5}$ & $7.231 \times 10^{10}$ & $2.87 \times 10^{-2}$ \\
\hline
\end{tabular}

Table II. Partition coefficients of VCM between liquid (water)/vapor phases using the bomb sampler (two-phase experiments)

\begin{tabular}{rcccccccc}
\hline \hline $\begin{array}{r}\text { Run } \\
\text { No. }\end{array}$ & $\begin{array}{r}\text { Temp, } \\
{ }^{\circ} \mathrm{C}\end{array}$ & $\begin{array}{c}\text { Tossure, } \\
\text { psi }\end{array}$ & $\begin{array}{c}\text { VCM mole } \\
\text { fraction } \\
\text { in vapor } \\
\text { phase }\end{array}$ & $\begin{array}{c}\text { Partial } \\
\text { pressure } \\
\text { of VCM, } \\
\text { psi }\end{array}$ & $\begin{array}{c}\text { Concn } \\
\text { of VCM } \\
\text { in water, } \\
\text { mol/ml }\end{array}$ & $\begin{array}{c}H_{\mathbf{L V}} \\
\text { dyn cm/ } \\
\text { mol }\end{array}$ & $\begin{array}{c}\% \text { Material- } \\
\text { balance } \\
\text { recovery }\end{array}$ & $\begin{array}{c}\text { Equilib- } \\
\text { rium } \\
\text { time, } \\
\text { min }\end{array}$ \\
\hline 1 & 25 & 15.46 & 0.9844 & 15.21 & $4.00 \times 10^{-5}$ & $2.62 \times 10^{10}$ & 102.46 & 120 \\
2 & 25 & 21.02 & 0.9297 & 19.54 & $4.70 \times 10^{-5}$ & $2.87 \times 10^{10}$ & 94.68 & 120 \\
3 & 25 & 34.98 & 0.9600 & 33.58 & $7.90 \times 10^{-5}$ & $2.93 \times 10^{10}$ & 97.60 & 120 \\
4 & 55 & 19.35 & 0.8900 & 17.22 & $2.50 \times 10^{-5}$ & $4.69 \times 10^{10}$ & 100.70 & 80 \\
5 & 55 & 32.06 & 0.9650 & 30.93 & $4.40 \times 10^{-5}$ & $4.85 \times 10^{10}$ & 100.60 & 80 \\
6 & 55 & 50.60 & 0.9800 & 49.59 & $8.30 \times 10^{-5}$ & $4.12 \times 10^{10}$ & 102.45 & 80 \\
7 & 65 & 20.90 & 0.8800 & 18.33 & $2.30 \times 10^{-5}$ & $5.51 \times 10^{10}$ & 98.00 & 70 \\
8 & 65 & 34.40 & 0.8300 & 28.55 & $3.40 \times 10^{-5}$ & $5.79 \times 10^{10}$ & 100.20 & 70 \\
9 & 65 & 59.63 & 0.9070 & 54.10 & $6.40 \times 10^{-5}$ & $5.83 \times 10^{10}$ & 99.50 & 70 \\
10 & 75 & 25.80 & 0.8500 & 21.93 & $1.90 \times 10^{-5}$ & $7.96 \times 10^{10}$ & 100.30 & 60 \\
11 & 75 & 47.83 & 0.8700 & 41.61 & $4.00 \times 10^{-5}$ & $7.17 \times 10^{10}$ & 99.20 & 60 \\
12 & 75 & 62.69 & 0.8700 & 54.54 & $5.00 \times 10^{-5}$ & $7.52 \times 10^{10}$ & 97.40 & 60 \\
13 & 85 & 28.69 & 0.7960 & 22.84 & $1.50 \times 10^{-5}$ & $10.49 \times 10^{10}$ & 93.00 & 45 \\
14 & 85 & 58.66 & 0.8050 & 47.22 & $3.16 \times 10^{-5}$ & $10.27 \times 10^{10}$ & 104.03 & 45 \\
15 & 85 & 72.83 & 0.8200 & 59.72 & $4.20 \times 10^{-5}$ & $9.79 \times 10^{10}$ & 95.10 & 45 \\
\hline
\end{tabular}


Table III. Partition coefficients of VCM between solid/liquid (water)/vapor phases using the bomb sampler

\begin{tabular}{|c|c|c|c|c|c|c|c|c|c|c|c|c|}
\hline $\begin{array}{l}\text { Run } \\
\text { No. }\end{array}$ & $\underset{{ }^{\circ} \mathrm{C}}{\mathrm{Temp}}$ & $\begin{array}{c}\text { Total } \\
\text { pressure, } \\
\text { psi }\end{array}$ & $\begin{array}{l}\text { VCM mole } \\
\text { fraction in } \\
\text { vapor } \\
\text { phase }\end{array}$ & $\begin{array}{l}\text { Partial } \\
\text { pressure } \\
\text { of VCM, } \\
\text { psi }\end{array}$ & $\begin{array}{l}\text { Concn of } \\
\text { VCM in } \\
\text { water, } \\
\mathrm{mol} / \mathrm{m} l\end{array}$ & $\begin{array}{l}\text { Concn of } \\
\text { VCM in } \\
\text { solid, } \\
\mathrm{mol} / \mathrm{m} l\end{array}$ & $\begin{array}{c}H_{\mathrm{SL}}, \\
(\mathrm{mol} / \mathrm{m} l) / \\
(\mathrm{mol} / \mathrm{m} l)\end{array}$ & $\begin{array}{c}H_{\mathrm{Lv}}, \\
\text { dyn cm/ } \\
\text { mol }\end{array}$ & $\begin{array}{c}H_{\mathrm{Sv}}, \\
\text { dyn cm/ } \\
\text { mol }\end{array}$ & $\begin{array}{c}\text { \% } \\
\text { Material- } \\
\text { balance } \\
\text { recovery }\end{array}$ & $\begin{array}{c}\text { Equilib- } \\
\text { rium } \\
\text { time, } \\
h\end{array}$ & $\begin{array}{l}\text { Compo- } \\
\text { nents } \\
\text { of slurry } \\
\text { used }^{\mathrm{a}}\end{array}$ \\
\hline 1 & 24 & 17.76 & 0.8992 & 15.970 & $4.09 \times 10^{-5}$ & $1.60 \times 10^{-3}$ & $2.56 \times 10^{-2}$ & $2.69 \times 10^{10}$ & $6.88 \times 10^{8}$ & 134.10 & 72 & A \\
\hline 2 & 28 & 9.98 & 0.4022 & 5.360 & $7.49 \times 10^{-6}$ & $2.88 \times 10^{-4}$ & $2.60 \times 10^{-2}$ & $3.69 \times 10^{10}$ & $9.59 \times 10^{8}$ & 111.05 & 168 & A \\
\hline 3 & 25 & 8.17 & 0.4700 & 3.840 & $9.90 \times 10^{-6}$ & $4.10 \times 10^{-4}$ & $2.41 \times 10^{-2}$ & $2.68 \times 10^{10}$ & $6.46 \times 10^{8}$ & 176.78 & 144 & A \\
\hline 4 & 25 & 6.37 & 0.2700 & 1.720 & $4.48 \times 10^{-8}$ & $2.94 \times 10^{-4}$ & $1.52 \times 10^{-2}$ & $2.64 \times 10^{10}$ & $4.03 \times 10^{8}$ & 125.23 & 192 & A \\
\hline 5 & 25 & 0.90 & 0.1280 & 0.115 & $2.56 \times 10^{-7}$ & $5.40 \times 10^{-6}$ & $4.74 \times 10^{-2}$ & $3.09 \times 10^{10}$ & $14.68 \times 10^{8}$ & - & 312 & B \\
\hline 7 & 80 & 9.20 & 0.2000 & 1.830 & $1.25 \times 10^{-6}$ & $4.60 \times 10^{-5}$ & $2.72 \times 10^{-2}$ & $10.07 \times 10^{10}$ & $2.74 \times 10^{9}$ & 100.80 & 18 & A \\
\hline 8 & 80 & 11.37 & 0.1700 & 1.930 & $1.40 \times 10^{-6}$ & $2.10 \times 10^{-5}$ & $6.67 \times 10^{-2}$ & $9.51 \times 10^{10}$ & $6.33 \times 10^{9}$ & 113.10 & 17 & A \\
\hline 9 & 80 & 28.24 & 0.6400 & 18.070 & $1.54 \times 10^{-5}$ & $4.48 \times 10^{-4}$ & $3.44 \times 10^{-2}$ & $8.09 \times 10^{10}$ & $2.77 \times 10^{9}$ & 96.90 & 16 & A \\
\hline 10 & 80 & 39.35 & 0.5200 & 20.460 & $2.39 \times 10^{-5}$ & $2.14 \times 10^{-3}$ & $1.12 \times 10^{-2}$ & $5.90 \times 10^{10}$ & $0.66 \times 10^{9}$ & 98.60 & 18 & A \\
\hline 11 & 80 & 40.67 & 0.6400 & 25.870 & $1.80 \times 10^{-5}$ & $1.14 \times 10^{-3}$ & $1.58 \times 10^{-2}$ & $9.91 \times 10^{10}$ & $1.57 \times 10^{9}$ & 100.14 & 19 & A \\
\hline 12 & 80 & 49.42 & 0.6200 & 30.640 & $2.60 \times 10^{-5}$ & $1.04 \times 10^{-3}$ & $2.50 \times 10^{-2}$ & $8.12 \times 10^{10}$ & $2.03 \times 10^{9}$ & 84.50 & 20 & A \\
\hline 13 & 80 & 56.44 & 0.5100 & 28.600 & $2.47 \times 10^{-5}$ & $1.37 \times 10^{-3}$ & $1.80 \times 10^{-2}$ & $7.98 \times 10^{10}$ & $1.44 \times 10^{9}$ & 100.60 & 21 & A \\
\hline 14 & 80 & 11.51 & 0.4200 & 4.790 & $2.56 \times 10^{-6}$ & $5.40 \times 10^{-5}$ & $4.74 \times 10^{-2}$ & $12.91 \times 10^{10}$ & $6.11 \times 10^{9}$ & 99.70 & 15 & A \\
\hline 16 & 93 & 16.37 & 0.0018 & 0.0295 & $2.24 \times 10^{-3}$ & $3.16 \times 10^{-6}$ & $0.71 \times 10^{-2}$ & $9.07 \times 10^{10}$ & $6.44 \times 10^{8}$ & - & 24 & $\mathrm{~B}$ \\
\hline 17 & 93 & 31.78 & 0.5400 & 17.1612 & $2.83 \times 10^{-6}$ & $3.91 \times 10^{-4}$ & $0.72 \times 10^{-2}$ & $4.18 \times 10^{11}$ & $3.03 \times 10^{9}$ & 96.65 & 26 & A \\
\hline 18 & 93 & 29.77 & 0.2400 & 7.1448 & $2.18 \times 10^{-6}$ & $2.58 \times 10^{-4}$ & $0.84 \times 10^{-2}$ & $2.26 \times 10^{11}$ & $1.91 \times 10^{9}$ & 93.65 & 4 & A \\
\hline 19 & 93 & 27.69 & 0.0011 & 0.0307 & $7.27 \times 10^{-8}$ & $7.19 \times 10^{-6}$ & $1.01 \times 10^{-2}$ & $2.91 \times 10^{10}$ & $2.94 \times 10^{8}$ & - & 6.5 & B \\
\hline 20 & 105 & 21.71 & 0.0026 & 0.0564 & $4.82 \times 10^{-8}$ & $6.50 \times 10^{-6}$ & $0.74 \times 10^{-2}$ & $8.07 \times 10^{10}$ & $5.98 \times 10^{8}$ & - & 6 & $\mathrm{~B}$ \\
\hline 21 & 105 & 28.03 & 0.0022 & 0.0617 & $3.20 \times 10^{-8}$ & $3.76 \times 10^{-6}$ & $0.85 \times 10^{-2}$ & $13.29 \times 10^{10}$ & $11.30 \times 10^{8}$ & - & 1 & B \\
\hline 22 & 105 & 31.20 & 0.1632 & 5.0918 & $2.59 \times 10^{-6}$ & $1.55 \times 10^{-4}$ & $1.67 \times 10^{-2}$ & $13.55 \times 10^{10}$ & $22.60 \times 10^{8}$ & 114.97 & 2.5 & A \\
\hline 23 & 108 & 31.44 & 0.2238 & 7.0363 & $3.71 \times 10^{-6}$ & $4.25 \times 10^{-4}$ & $0.87 \times 10^{-2}$ & $13.08 \times 10^{10}$ & $11.40 \times 10^{8}$ & 102.10 & 4.5 & $\mathrm{~A}$ \\
\hline 24 & 105 & 34.90 & 0.2969 & 10.3600 & $6.05 \times 10^{-6}$ & $4.72 \times 10^{-4}$ & $1.28 \times 10^{-2}$ & $11.81 \times 10^{10}$ & $15.10 \times 10^{8}$ & 104.36 & 8 & A \\
\hline 25 & 105 & 44.77 & 0.3458 & 15.4800 & $8.90 \times 10^{-6}$ & $1.03 \times 10^{-3}$ & $0.79 \times 10^{-2}$ & $13.19 \times 10^{10}$ & $10.36 \times 10^{8}$ & 98.25 & 6 & A \\
\hline
\end{tabular}


Table IV. Partition coefficients of VCM between solid/liquid/vapor phases (1:1 ethanol-water system) using the bomb sampler

\begin{tabular}{|c|c|c|c|c|c|c|c|c|c|c|c|}
\hline $\begin{array}{l}\text { Run } \\
\text { No. }\end{array}$ & $\underset{{ }^{\circ} \mathrm{C}}{\mathrm{Temp}}$ & $\begin{array}{c}\text { Total } \\
\text { pressure, } \\
\text { psi }\end{array}$ & $\begin{array}{l}\text { VCM mole } \\
\text { fraction in } \\
\text { vapor } \\
\text { phase }\end{array}$ & $\begin{array}{c}\text { Partial } \\
\text { pressure } \\
\text { of VCM, } \\
\text { psi }\end{array}$ & $\begin{array}{l}\text { Concn of } \\
\text { VCM in } \\
\text { liquid, } \\
\mathrm{mol} / \mathrm{ml}\end{array}$ & $\begin{array}{l}\text { Concn of } \\
\text { VCM in } \\
\text { solid, } \\
\mathrm{mol} / \mathrm{m} l\end{array}$ & $\begin{array}{c}H_{\mathrm{SL}}, \\
(\mathrm{mol} / \mathrm{m} l) / \\
(\mathrm{mol} / \mathrm{m} l)\end{array}$ & $\begin{array}{c}H_{\mathrm{LV}}, \\
\text { dyn } \mathrm{cm} / \mathrm{mol}\end{array}$ & $\begin{array}{c}H_{\mathrm{Sv}}, \\
\text { dyn } \mathrm{cm} / \mathrm{mol}\end{array}$ & $\begin{array}{l}\text { Equilib- } \\
\text { rium } \\
\text { time, } \\
h\end{array}$ & $\begin{array}{l}\text { Compo- } \\
\text { nents } \\
\text { of slurry } \\
\text { used }^{\mathrm{a}}\end{array}$ \\
\hline 1 & 27 & 10.39 & 0.5700 & 5.9200 & $6.90 \times 10^{-6}$ & $2.10 \times 10^{-4}$ & $3.29 \times 10^{-2}$ & $5.92 \times 10^{10}$ & $1.94 \times 10^{9}$ & 41 & A \\
\hline 2 & 27 & 6.51 & 0.6200 & 4.0400 & $9.22 \times 10^{-6}$ & $7.70 \times 10^{-4}$ & $1.20 \times 10^{-2}$ & $3.02 \times 10^{10}$ & $3.59 \times 10^{8}$ & 27 & A \\
\hline 3 & 25 & 1.64 & 0.0053 & 0.0087 & $1.20 \times 10^{-7}$ & $1.66 \times 10^{-5}$ & $0.72 \times 10^{-2}$ & $4.99 \times 10^{9}$ & $3.59 \times 10^{7}$ & 168 & B \\
\hline 4 & 27 & 1.44 & 0.0072 & 0.0104 & $9.17 \times 10^{-8}$ & $2.38 \times 10^{-5}$ & $0.36 \times 10^{-2}$ & $7.79 \times 10^{9}$ & $3.01 \times 10^{7}$ & 180 & B \\
\hline 5 & 25 & 1.02 & 0.0307 & 0.0313 & $6.50 \times 10^{-7}$ & $5.40 \times 10^{-5}$ & $1.20 \times 10^{-2}$ & $3.24 \times 10^{9}$ & $3.99 \times 10^{7}$ & 140 & B \\
\hline 6 & 50 & 10.00 & 0.4800 & 4.8000 & $4.30 \times 10^{-5}$ & $4.40 \times 10^{-4}$ & $9.77 \times 10^{-2}$ & $7.72 \times 10^{9}$ & $7.52 \times 10^{8}$ & 17 & A \\
\hline 7 & 50 & 5.25 & 0.1000 & 0.5250 & $5.80 \times 10^{-6}$ & $1.70 \times 10^{-4}$ & $3.41 \times 10^{-2}$ & $6.24 \times 10^{9}$ & $2.12 \times 10^{8}$ & 16 & A \\
\hline 8 & 50 & 4.08 & 0.0053 & 0.0216 & $2.24 \times 10^{-7}$ & $1.90 \times 10^{-5}$ & $1.18 \times 10^{-2}$ & $6.62 \times 10^{9}$ & $7.86 \times 10^{7}$ & 15 & B \\
\hline 9 & 50 & 4.49 & 0.0050 & 0.0225 & $2.08 \times 10^{-7}$ & $1.83 \times 10^{-5}$ & $1.14 \times 10^{-2}$ & $7.44 \times 10^{9}$ & $2.34 \times 10^{7}$ & 18 & B \\
\hline 10 & 50 & 4.20 & 0.0047 & 0.0197 & $2.20 \times 10^{-7}$ & $2.60 \times 10^{-5}$ & $0.85 \times 10^{-2}$ & $6.18 \times 10^{9}$ & $5.23 \times 10^{7}$ & 17 & B \\
\hline 11 & 80 & 14.63 & 0.0035 & 0.0512 & $5.12 \times 10^{-7}$ & $2.64 \times 10^{-5}$ & $1.94 \times 10^{-2}$ & $6.89 \times 10^{9}$ & $1.34 \times 10^{8}$ & 21 & B \\
\hline $12^{\mathrm{b}}$ & 80 & 29.56 & 0.0007 & 0.0207 & $6.24 \times 10^{-7}$ & $1.96 \times 10^{-5}$ & $3.18 \times 10^{-2}$ & $2.28 \times 10^{9}$ & $7.28 \times 10^{7}$ & 22 & B \\
\hline
\end{tabular}

${ }^{a} \mathrm{~A}$ is VCM-free dry PVC resin +1: 1 ethanol-water +VCM gas. B is PVC slurry +1:1 ethanol-water.

b $100-\%$ ethanol as liquid phase. 
Table V. Equilibrium partition parameters of VCM in various solvents and $\mathrm{PVC}^{\mathrm{a}}$

\begin{tabular}{|c|c|c|c|c|}
\hline & \multicolumn{2}{|c|}{$C_{\mathrm{L}}=K C_{\mathrm{S}}{ }^{n}$} & \multicolumn{2}{|c|}{$C_{\mathrm{L}}=K_{1} C_{\mathrm{S}} /\left(1+K_{2} C_{\mathrm{S}}\right)$} \\
\hline & $n$ & $K$ & $K_{1}$ & $K_{2}$ \\
\hline $\begin{array}{l}\text { In unplasticized PVC and water at room } \\
\text { temperature (Rutgers University) }\end{array}$ & 1.40 & 0.00082 & 0.0082 & $-3.30 \times 10^{-4}$ \\
\hline $\begin{array}{l}\text { In plasticized PVC and water at room } \\
\text { temperature (Rutgers University) }\end{array}$ & 0.93 & 0.096 & 0.0663 & $7.57 \times 10^{-6}$ \\
\hline In unplasticized PVC and water at $195^{\circ} \mathrm{C}(\mathrm{APCI})$ & 1.043 & 0.0097 & 0.0136 & $1.87 \times 10^{-6}$ \\
\hline In unplasticized PVC and water at $93^{\circ} \mathrm{C}$ (APCI) & 1.011 & 0.011 & 0.0126 & $6.59 \times 10^{-8}$ \\
\hline In unplasticized PVC and water at $80^{\circ} \mathrm{C}$ (APCI) & 0.72 & 0.52 & 0.0694 & $3.30 \times 10^{-5}$ \\
\hline $\begin{array}{l}\text { In unplasticized PVC and water at room } \\
\text { temperature (APCI) }\end{array}$ & 0.87 & 0.13 & 0.0344 & $5.66 \times 10^{-7}$ \\
\hline $\begin{array}{l}\text { In unplasticized PVC and 1: } 1 \text { ethanol-water } \\
\text { at } 50^{\circ} \mathrm{C}(\mathrm{APCI})\end{array}$ & 1.67 & 0.00015 & 0.0154 & $-5.17 \times 10^{-5}$ \\
\hline $\begin{array}{l}\text { In unplasticized PVC and } 1: 1 \text { ethanol-water } \\
\text { at room temperature (APCI) }\end{array}$ & 1.31 & 0.0012 & 0.0101 & $-1.75 \times 10^{-5}$ \\
\hline
\end{tabular}

in the solid phase increases to $100,000 \mathrm{ppm}, H_{\mathrm{SL}}$ assumes a value which is almost independent of temperature. At lower concentration, the $H_{\mathrm{SL}}$ value seems to exhibit a maxima near the glasstransition temperature of PVC (approximately $80^{\circ} \mathrm{C}$ ). This observed maxima in $H_{\text {SL }}$ could have resulted from the experimental errors as described at the end of last section.

By comparing Figures 6 and 7, it is interesting to note that a $1: 1$ ethanol-water mixture has a lower $H_{\mathrm{SL}}$ than pure water.

The equilibrium concentration in liquid and solid phases at a given temperature are correlated in terms of the Freundlich isotherm (eq 2) and the Langmuir isotherm (eq 4).

$$
C_{\mathrm{L}}=K C_{\mathrm{s}}{ }^{n}
$$

or,

$$
\begin{aligned}
H_{\mathrm{SL}} & =K C_{\mathrm{s}}{ }^{n-1} \\
C_{\mathrm{L}} & =\frac{K_{1} C_{\mathrm{S}}}{1+K_{2} C_{\mathrm{S}}}
\end{aligned}
$$

or,

$$
H_{\mathrm{sL}}=\frac{K_{1}}{1+K_{2} C_{\mathrm{s}}}
$$

The constants for the two isotherms are given in Table V. A value for $n$ other than unity in eq 2 and a nonzero value of $K_{2}$ in eq 4 represent a departure from linear equilibrium. Both eq 2 and 4 fit the experimental data in the range of concen- trations investigated. However, at very low concentrations when the equilibrium must be linear, the Langmuir isotherm will be a better representation. At temperatures above the glass transition, the constant $n$ of eq 2 is essentially equal to unity and the equilibrium function is again linear. This is consistent with the observation of Berens ${ }^{5}$ that VCM sorption follows Henry's law above the glasstransition temperature.

Acknowledgments. The authors are grateful to Drs. G. J. Mantell, P. L. T. Brian, M. Chen, and D. Pesuit, and Mr. C. H. Worman for their valuable consultations and encouragements in this work.

\section{REFERENCES}

1. Federal Register, 39, 194 (1975).

2. Federal Register, 40, 248 (1975).

3. Federal Register, 40, 71 (1975).

4. G. J. Mantell, J. T. Barr, R. K. S. Chan, M. Langsam, P. L. T. Brian, J. T. Cheng, D. H. Francke, R. E. Grandin, E. H. Hollister, D. Pesuit, F. L. Riddle, and C. H. Worman, Chem. Eng. Progr., 71 (9), 54-62 (1975).

5. A. R. Berens, Polym. Prepr., 15 (2), 203 (1975).

6. J. R. Morano, Ph. D. Thesis, Rutgers University (1975).

7. G. A. Daniels and D. E. Proctor, report from Ethyl Corporation, also the same authors in Technical/Engineering (1975). 